\title{
Anti-glomerular basement membrane disease in children: a brief overview
}

\author{
Thomas Dowsett ${ }^{1} \cdot$ Louise Oni ${ }^{2,3}$
}

Received: 3 June 2021 / Revised: 28 September 2021 / Accepted: 29 September 2021 / Published online: 12 November 2021

(c) The Author(s) 2021

\begin{abstract}
Anti-glomerular basement membrane disease (Anti-GBM), previously known as Goodpasture syndrome, is an extremely rare cause of rapidly progressive glomerulonephritis and chronic kidney disease stage 5 (CKD5) in children. It is associated with acute pulmonary haemorrhage and it has a poor prognosis. It is classified as an autoimmune, small-vessel vasculitis caused by autoantibody formation against the alpha-3 chain in type IV collagen found in the glomerular basement membrane. Evidence of anti-GBM antibodies in serum or histologically are required for diagnosis. Treatment in children is based on very limited adult data and often involves the use of acute apheresis to rapidly remove circulating factors coupled with intensive immunosuppression such as cyclophosphamide and intravenous corticosteroids. There is also an emerging role for the use of biologic agents such as B cell depletion. The evidence base in children with anti-GBM disease is extremely limited. Multi-centre international collaboration is required to provide insight into this disease, better describe its prognosis and work towards improving outcomes. This review article summarises the key features of this disease in children, highlights treatment options and considers areas of unmet need.
\end{abstract}

Keywords Anti-GBM · Glomerulonephritis · Children

\section{Introduction}

Anti-glomerular basement membrane disease (Anti-GBM), previously known as Goodpasture's disease or syndrome, is an extremely rare cause of glomerulonephritis (GN) and chronic kidney disease stage 5 (CKD 5) in children. The literature relating to anti-GBM disease in children is limited to a small number of case reports and retrospective case series. Although rare, it is characterised by rapidly progressive glomerulonephritis (RPGN) and it is associated with a poor prognosis [1]. This concise review summarises the key

Louise Oni

louise.oni@liverpool.ac.uk

1 Department of Paediatric Nephrology, Royal Manchester Children's Hospital, Oxford Road, Manchester M13 9WL, UK

2 Department of Paediatric Nephrology, Alder Hey Children's NHS Foundation Trust Hospital, Eaton Road, Liverpool L12 2AP, UK

3 Department of Women's and Children's Health, Institute of Life Course and Medical Sciences, University of Liverpool, Eaton Road, Liverpool L12 2AP, UK features of this disease, discusses management, including the role of apheresis therapy, and considers areas of unmet need to help improve future outcomes in children.

\section{Incidence and clinical features}

Anti-GBM disease is extremely uncommon in children; however, it is responsible for $\sim 20 \%$ of all causes of RPGN. Defining its precise incidence in children remains a challenge. In adults it has an incidence of $0.5-1.0$ cases per million population per year [2]. In adults, it shows a bimodal distribution with peaks in the $3^{\text {rd }}$ and $6^{\text {th }}$ decades of life [3]. The US data determined that anti-GBM disease accounted for $0.4 \%$ (24/6,560 cases) of all paediatric CKD 5 [4]. Other studies have reported that anti-GBM disease accounts for $3 \%$ of crescenteric GN in children [5]. The disease prevalence demonstrates some seasonal variation and geographical clustering which may be due to infectious triggers that include upper and lower respiratory tract infections such as influenza A and more recently the severe acute respiratory syndrome coronavirus-2 (SARS-COV-2) evident during the COVID-19 pandemic $[6,7]$. The sparse literature suggests a 
2:1 predominance in females in children. In adults, it appears to be more common in males [8].

The disease classically presents with rapidly progressive GN in $80-90 \%$ of cases necessitating acute kidney replacement therapy and this presentation is similar between adults and children with the disease [6]. Most patients report a degree of prodromal illness including lethargy and malaise in the weeks prior to presentation. Up to $60 \%$ of cases will also develop pulmonary haemorrhage while a minority may present with pulmonary involvement in isolation $[6,8]$. Pulmonary involvement can vary significantly, from lifethreatening haemoptysis to asymptomatic radiographic or bronchoscopy findings alone [8, 9]. Pulmonary symptoms commonly include shortness of breath, wheeze, haemoptysis and chest pain. Signs and symptoms of kidney involvement are those typical of an acute GN including severe hypertension and fluid overload. Haematuria may be either microscopic or macroscopic. Cerebral involvement due to primary cerebral small vessel angiitis is reported and usually presents with seizures $[8,10]$. In adults, exposure to cigarette smoking and hydrocarbons is a risk factor for developing the disease, but this has not been reflected in paediatric case reports and may be due to the low likelihood of exposure to these triggers in children [11].

Detection of anti-GBM antibodies, either in serum or histologically, assist in formulating the diagnosis [3]. In approximately $10 \%$ of patients with anti-GBM disease circulating antibodies would not be detected. This may be due to either false negative results within the enzyme immunoassays or due to genuine absence of circulating antibodies, and therefore, histological evidence of disease, through lung or kidney tissue, is important in cases where there remains a high clinical suspicion of disease [12]. It is the antibody deposition that distinguishes anti-GBM disease from other types of glomerulo-nephritides such as post-infectious, immune-complex and isolated antinuclear cytoplasmic antibody (ANCA)-associated GN. Kidney histology classically identifies extensive crescent formation affecting $>80 \%$ of the glomeruli on light microscopy and immunofluorescence (IF) detects linear IgG deposition along the GBM. In some cases with severe, extensive glomerular inflammation, the histological features may be distorted and challenging to accurately report. Additionally, the linear IgG deposition may also be seen in other inflammatory diseases including diabetes, paraproteins, lupus nephritis or fibrillary GN. Genetic studies have shown an association between Human Leucocyte Antigens (HLA) DRBI*1051 and DRBI*1502 while HLA-DR7 and DR1 appear to be somewhat protective [3].

\section{Disease pathophysiology}

The glomerular basement membrane is a critical part of the glomerular filtration barrier. Type IV collagen is a major contributor to maintaining the stability of the GBM [13]. Anti-GBM disease is classified as an autoimmune, smallvessel vasculitis caused by pathogenic autoantibody formation usually of the IgG class, with IgG1 and IgG3 predominating, that target the alpha- 3 chain in type IV collagen found in the GBM (Fig. 1) [3]. This collagen chain subtype is present in both alveolar and kidney basement membranes explaining the disease phenotype. Binding of IgG antibodies to the GBM lead to classical complement activation and a neutrophilic inflammatory response [3]. The epitope responsible for antibody binding is hidden within the protein hexamer of type IV collagen and two conformational epitopes have been defined at different residues within the alpha-3-NC1 domain that are believed to correlate with outcomes (reported as type EA and EB) [14]. It is proposed that an immunological or environmental exposure, such as infections, cigarette smoking or hydrocarbons, uncover the $\mathrm{NC} 1$ domain that then acts as an antigen to the immune system [15]. The innate immune system also contributes to the inflammatory process of this disease with $\mathrm{T}$ cells contributing to direct cell mediated glomerular injury and $\mathrm{T}$ regulatory cells proposed to have the ability to suppress aspects of the autoimmune and alloimmune response [16].

\section{Overlap with other conditions}

ANCA-associated vasculitis (AAV) and anti-GBM are included in the spectrum of pulmonary-renal syndromes as they may present with a similar combination of kidney and lung manifestations [17]. Cases of dual ANCA and anti-GBM antibody positivity are widely reported (17\% of reported cases in children) and it has been suggested that the initial presence of ANCA may be the trigger responsible for exposing the epitope in the alpha-3 chain [8]. Dual positivity is associated with a poorer prognosis, and thus, early, aggressive treatment is recommended [18]. Patients may also present with features overlapping with membranous nephropathy at a higher rate than would be expected by chance and atypical presentations of this disease are reported [19].

In patients with Alport syndrome, genetic mutations coding for the type IV collagen chains are responsible for progressive kidney disease [6]. Cases of allo-immune production of anti-GBM antibodies (de-novo anti-GBM) have occurred following kidney transplantation in patients with Alport syndrome [6]. It is important to note that this occurs more frequently in those with gene deletions as opposed to 


\section{Type 4 Collagen}

Helical chains unique to the glomerulus and alveoli

\section{$\alpha 5$}

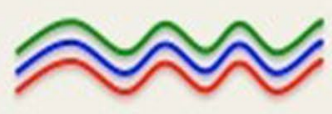

\section{Anti-GBM antibodies}
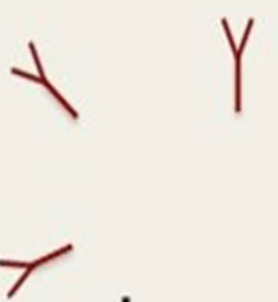

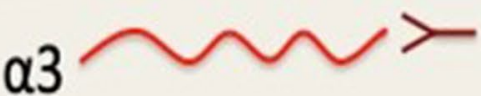

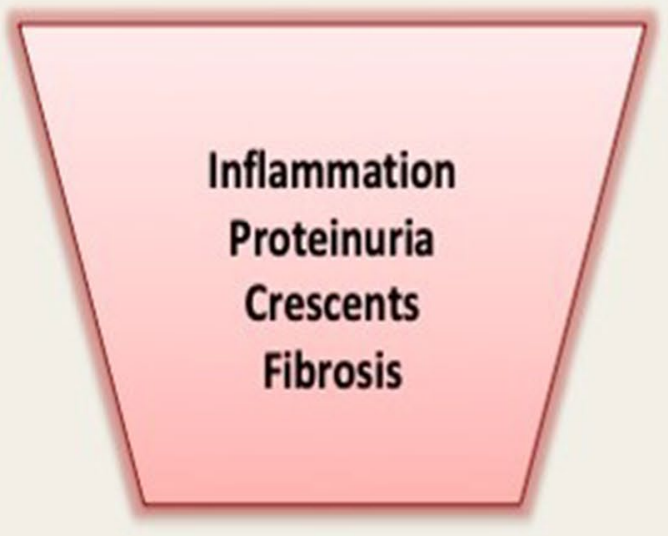
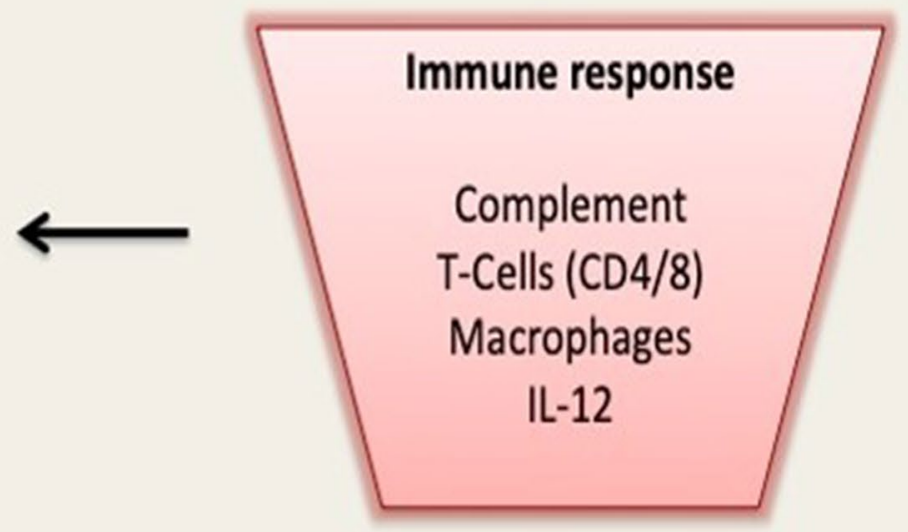

Fig. 1 The $\alpha 3,4,5$ chains that are specific to type IV collagen found in the basement membranes of the glomerulus and alveoli. Environmental exposure to certain risk factors reveal hidden antigenic epitopes on the $\alpha 3$ chain leading to the autoimmune production of anti-GBM antibodies and the subsequent inflammatory response

\section{Management}

The management of anti-GBM disease in children is based on the approach derived from the management in adult disease and clearly described within the recent KDIGO glomerular disease guidelines (2021) [22]. Principles include removal of the pathogenic circulating antibody and potential immune mediators with acute apheresis; ceasing production of antibodies with cyclophosphamide and/or B cell depleting agents; and reducing inflammation with corticosteroids and/ or adjunctive immune modifying agents such as mycophenolate mofetil (MMF) [23]. Supportive therapy includes the use of kidney replacement therapy, usually haemodialysis and antihypertensive agents when needed. There are no literature reports using acute peritoneal dialysis in this condition probably due to the need for secure vascular access to permit apheresis therapy. 


\section{Apheresis therapy}

Anti-GBM is a recognised indication for the use of apheresis treatment in cases presenting with acute GN not requiring dialysis who have diffuse alveolar haemorrhage, or dialysis dependent acute GN without diffuse alveolar haemorrhage [24]. Even in cases where irreversible crescenteric CKD 5 is present, aggressive treatment should still be initiated if there is evidence of diffuse alveolar haemorrhage due to its associated risk with mortality (100\% mortality from historical data) [23]. Guidelines suggest a $1-1.5$ plasma volume exchange using either fresh frozen plasma or 5\% albumin depending on the risk of bleeding. Daily or alternate day treatment with at least 14 sessions or until antibodies are no longer detectable are generally recommended [25]. As children are typically also treated with aggressive immunosuppression, it is difficult to reliably report on the effectiveness of apheresis on kidney outcomes. A review of the apheresis protocols used within the literature in children with antiGBM is summarised in Table 1 [8, 26-32]. Immunoadsorption leading to more specific removal of pathogenic immunoglobulins has been reported [33]. A comparison study 'of immunoadsorption' in adults failed to demonstrate any additional benefit over double filtration plasmapheresis [34].

\section{Immunosuppressive therapy}

First-line immunosuppressive therapy in this disease is cyclophosphamide and high dose corticosteroids as recommended by the KDIGO guidelines for the management of GN [23]. Cyclophosphamide has recognised toxic side effects that include gonadal toxicity that seems to be influenced by the total cumulative dose received and the stage of pubertal development in the child. Pre-pubertal children are at lowest risk of future gonadal failure with rates reported to be $<10 \%$ in pre-pubertal boys receiving $<400 \mathrm{mg} / \mathrm{kg}$ total dose of cyclophosphamide [35]. Rituximab, a B-cell depleting agent, is advised if cyclophosphamide is contra-indicated and it could be considered as a disease adjunct in severe cases. Small case series in adults demonstrated measurable improvement in respiratory disease using rituximab as an induction agent, but they failed to demonstrate improvements in kidney outcomes [36]. MMF has been used in a small number of patients with reported success for disease induction and maintenance [37].

\section{Prognosis}

Unlike many other autoimmune conditions, anti-GBM disease does not tend to run a relapsing, remitting course. The initial presentation is therefore usually responsible for disease-associated morbidity and mortality. In a large series of adult patients ( $n=119)$, a third of patients required intensive care unit admission on first presentation, $78 \%$ needed kidney replacement therapy (KRT) and $82 \%$ received plasma exchange therapy. The 1-year survival rate was $95 \%$ and the 3 -year survival rate was $92 \%$ [38]. In this series, the use of plasma exchange was associated with better survival. Regarding morbidity, kidney failure is the largest consequence of this disease with rates $>46 \%$ in adult patients and the risk of kidney failure is associated with increased creatinine at presentation, need for KRT, less cumulative dose of cyclophosphamide, and histological features that include extra capillary proliferation, capsular rupture, interstitial fibrosis and hyaline thrombi [38]. The literature surrounding the prognosis in children is very limited. In one case series (US) of four paediatric patients, one died at presentation from pulmonary haemorrhage and three patients received the treatment course outlined above. Of these patients, one recovered kidney function at 1 year and two required ongoing kidney replacement therapy and eventual transplantation, suggesting a similar 50\% rate of kidney failure in children [11]. KDIGO recommends a period of 6 months with undetectable levels of anti-GBM antibody prior to considering transplantation [23]. Graft loss and mortality post-transplant are reported to be similar for anti-GBM disease when compared to other immune-mediated diseases and disease recurrence following transplantation is rare but recognised in $2-4 \%$ of patients $[39,40]$.

\section{Areas of unmet need}

The evidence base for the diagnosis and management of anti-GBM disease in children is derived from adult data. The proposed standard treatments are based on adult studies and seem to be well accepted [22]. Further research is needed to identify treatment protocols that would improve current standard therapy in this rare condition. These studies will need to involve adult patients due to the rarity of the disease in children. Improved understanding of the immune mechanisms involved in this disease will identify novel targets for treatment, such as specific biologic inhibitors of the immune system or exploring the role of the $\mathrm{T}$ cell functions, particularly $\mathrm{T}$ regulatory cells that may help to suppress disease. Pre-clinical studies have demonstrated promise using Fostamatinib treatment, an inhibitor of the tyrosine kinase signalling pathway, in its ability to interfere with crescent formation. National and international collaboration to prospectively report cases would identify associations in the development of the disease, define current practice and provide more up to date outcomes of the current treatment protocols used in children. 


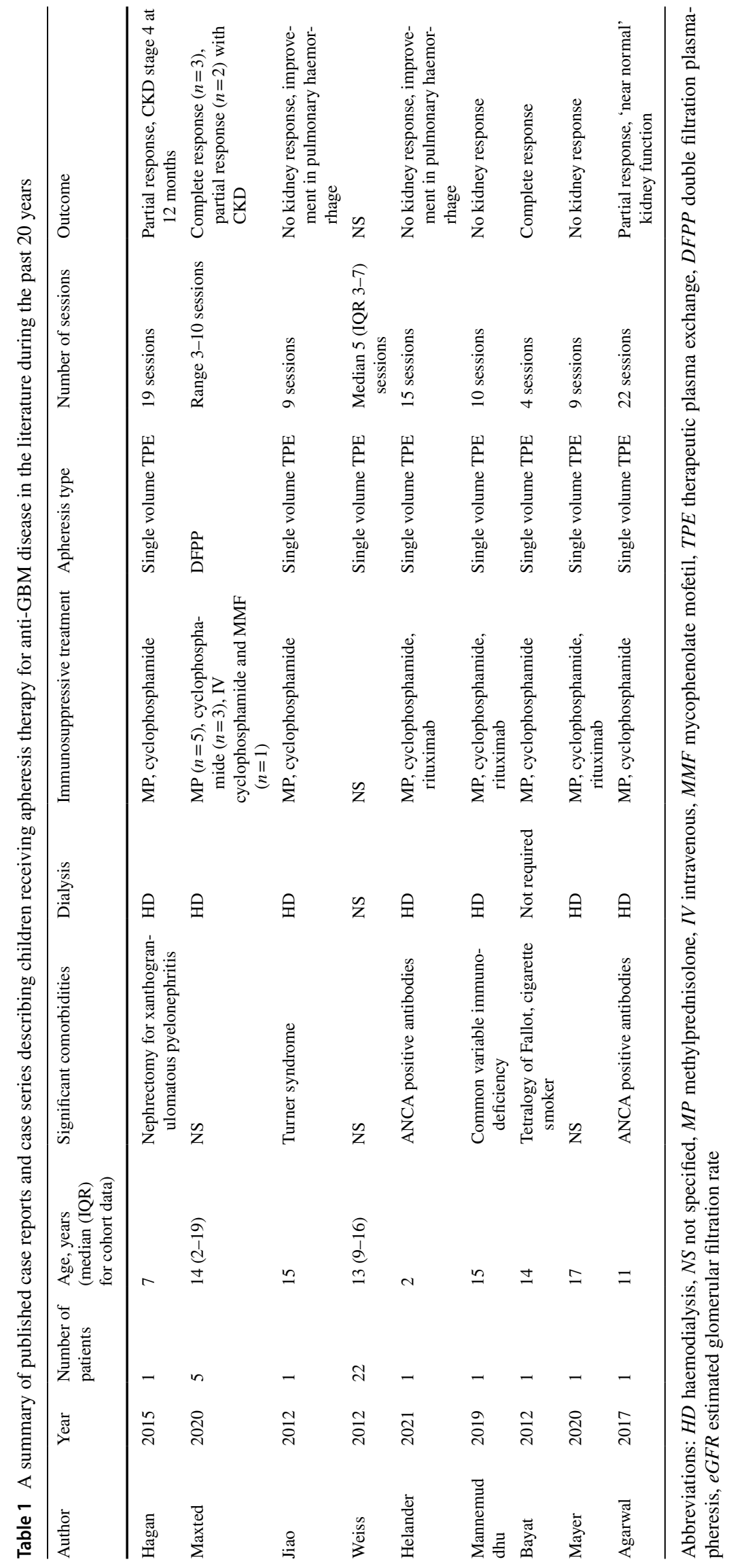




\section{Summary}

Anti-GBM disease is a rare entity in childhood but it is associated with a significant level of morbidity and acute mortality. The autoimmune development of antibodies towards type IV collagen in the glomerular and alveolar basement membranes leads to patients typically presenting with RPGN and pulmonary haemorrhage. Evidence of anti-GBM antibodies in serum or histologically is required for diagnosis. Treatment in children is based on adult data and involves the use of apheresis and intensive, strong immunosuppression such as cyclophosphamide. Multi-centre international collaboration is required to provide insight into this disease and to improve its management in children.

\section{Declarations}

Conflict of interest The authors declare no competing interests.

Open Access This article is licensed under a Creative Commons Attribution 4.0 International License, which permits use, sharing, adaptation, distribution and reproduction in any medium or format, as long as you give appropriate credit to the original author(s) and the source, provide a link to the Creative Commons licence, and indicate if changes were made. The images or other third party material in this article are included in the article's Creative Commons licence, unless indicated otherwise in a credit line to the material. If material is not included in the article's Creative Commons licence and your intended use is not permitted by statutory regulation or exceeds the permitted use, you will need to obtain permission directly from the copyright holder. To view a copy of this licence, visit http://creativecommons.org/licenses/by/4.0/.

\section{References}

1. Oni L (2021) Paediatric immune-mediated renal disease: an overview. Nephrol Dial Transplant 36:596-598. https://doi.org/ 10.1093/ndt/gfz184

2. Silvarino R, Noboa O, Cervera R (2014) Anti-glomerular basement membrane antibodies. Isr Med Assoc J 16:727-732

3. Hellmark T, Segelmark M (2014) Diagnosis and classification of Goodpasture's disease (anti-GBM). J Autoimmun 48-49:108112. https://doi.org/10.1016/j.jaut.2014.01.024

4. Collins AJ, Foley RN, Herzog C, Chavers B, Gilbertson D, Ishani A, Kasiske B, Liu J, Mau LW, McBean M, Murray A, St Peter W, Guo H, Li Q, Li S, Li S, Peng Y, Qiu Y, Roberts T, Skeans M, Snyder J, Solid C, Wang C, Weinhandl E, Zaun D, Arko C, Chen SC, Dalleska F, Daniels F, Dunning S, Ebben J, Frazier E, Hanzlik C, Johnson R, Sheets D, Wang X, Forrest B, Constantini E, Everson S, Eggers P, Agodoa L (2009) United States Renal Data System 2008 Annual Data Report. Am J Kidney Dis 53(1 Suppl):S1-374. https://doi.org/10.1053/j.ajkd.2008.10.005

5. Maliakkal JG, Hicks MJ, Michael M, Selewski DT, Twombley K, Rheault MN, Seamon M, Misurac JM, Tran CL, Reyes L, Flynn JT, Onder AM, Constantinescu AR, Singh V, Pan C, Omoloja A, Wu Q, Smoyer WE, Hidalgo G, Wenderfer SE (2020) Renal survival in children with glomerulonephritis with crescents: a pediatric nephrology research consortium cohort study. J Clin Med 9:2385. https://doi.org/10.3390/jcm9082385

6. McAdoo SP, Pusey CD (2017) Anti-glomerular basement membrane disease. Clin J Am Soc Nephrol 12:1162-1172. https://doi. org/10.2215/CJN.01380217

7. Prendecki M, Clarke C, Cairns T, Cook T, Roufosse C, Thomas D, Willicombe M, Pusey CD, McAdoo SP (2020) Anti-glomerular basement membrane disease during the COVID-19 pandemic. Kidney Int 98:780-781. https://doi.org/10.1016/j.kint.2020.06. 009

8. Bayat A, Kamperis K, Herlin T (2012) Characteristics and outcome of Goodpasture's disease in children. Clin Rheumatol 31:1745-1751. https://doi.org/10.1007/s10067-012-2062-9

9. Lazor R, Bigay-Game L, Cottin V, Cadranel J, Decaux O, Fellrath JM, Cordier JF, Grouped'Etudes et de Recherche sur les Maladies OrphelinesPulmonaires (GERMOP) and the Swiss Group for Interstitial and Orphan Lung Diseases (SIOLD) (2007) Alveolar hemorrhage in anti-basement membrane antibody disease: a series of 28 cases. Medicine (Baltimore) 86:181-193. https://doi.org/10. 1097/md.0b013e318067da56

10. Gittins N, Basu A, Eyre J, Gholkar A, Moghal N (2004) Cerebral vasculitis in a teenager with Goodpasture's syndrome. Nephrol Dial Transplant 19:3168-3171. https://doi.org/10.1093/ndt/ gfh448

11. Williamson SR, Phillips CL, Andreoli SP, Nailescu C (2011) A 25-year experience with pediatric anti-glomerular basement membrane disease. Pediatr Nephrol 26:85-91. https://doi.org/10.1007/ s00467-010-1663-2

12. Vries TB, Boerma S, Doornebal J, Dikkeschei B, Stegeman C, Veneman TF (2017) Goodpasture's syndrome with negative antiglomerular basement membrane antibodies. Eur J Case Rep Intern Med 4:000687. https://doi.org/10.12890/2017_000687

13. Chew C, Lennon R (2018) Basement membrane defects in genetic kidney diseases. Front Pediatr 6:11. https://doi.org/10. 3389/fped.2018.00011

14. Yang R, Hellmark T, Zhao J, Cui Z, Segelmark M, Zhao MH, Wang HY (2009) Levels of epitope-specific autoantibodies correlate with renal damage in anti-GBM disease. Nephrol Dial Transplant 24:1838-1844. https://doi.org/10.1093/ndt/gfn761

15. Hudson BG, Tryggvason K, Sundaramoorthy M, Neilson EG (2003) Alport's syndrome, Goodpasture's syndrome, and type IV collagen. N Engl J Med 348:2543-2556. https://doi.org/10. 1056/NEJMra022296

16. Salama AD, Chaudhry AN, Holthaus KA, Mosley K, Kalluri R, Sayegh MH, Lechler RI, Pusey CD, Lightstone L (2003) Regulation by CD25+ lymphocytes of autoantigen-specific T-cell responses in Goodpasture's (anti-GBM) disease. Kidney Int 64:1685-1694. https://doi.org/10.1046/j.1523-1755.2003. 00259.x

17. Bogdanovic R, Minic P, Markovic-Lipkovski J, Stajic N, Savic N, Rodic M (2013) Pulmonary renal syndrome in a child with coexistence of anti-neutrophil cytoplasmic antibodies and antiglomerular basement membrane disease: case report and literature review. BMC Nephrol 14:66. https://doi.org/10.1186/ 1471-2369-14-66

18. Mastrangelo A, Serafinelli J, Giani M, Montini G (2020) Clinical and pathophysiological insights into immunological mediated glomerular diseases in childhood. Front Pediatr 8:205. https://doi. org/10.3389/fped.2020.00205

19 Speer C, Gaida MM, Waldherr R, Nusshag C, Kalble F, Zeier M (2018) Membranous nephropathy followed by anti-glomerular basement disease: a case report and review of clinical presentation and treatment. SAGE Open Med Case Rep 6:2050313X1880762. https://doi.org/10.1177/2050313X18807621

20. Browne G, Brown PA, Tomson CR, Fleming S, Allen A, Herriot R, Pusey CD, Rees AJ, Turner AN (2004) Retransplantation in 
Alport post-transplant anti-GBM disease. Kidney Int 65:675-681. https://doi.org/10.1111/j.1523-1755.2004.00428.x

21. Byrne MC, Budisavljevic MN, Fan Z, Self SE, Ploth DW (2002) Renal transplant in patients with Alport's syndrome. Am J Kidney Dis 39:769-775. https://doi.org/10.1053/ajkd.2002.31997

22. Rovin BH, Adler SG, Barratt J, Bridoux F, Burdge KA, Chan TM, Cook HT, Fervenza FC, Gibson KL, Glassock RJ, Jayne DRW, Jha V, Liew A, Liu ZH, Mejia-Vilet JM, Nester CM, Radhakrishnan J, Rave EM, Reich HN, Ronco P, Sanders JF, Sethi S, Suzuki Y, Tang SCW, Tesar V, Vivarelli M, Wetzels JFM, Lytvyn L, Craig JC, Tunnicliffe DJ, Howell M, Tonelli MA, Cheung M, Earley A, Floege J (2021) Executive summary of the KDIGO 2021 guideline for the management of glomerular diseases. Kidney Int 100:753779. https://doi.org/10.1016/j.kint.2021.05.015

23. Kidney Disease: Improving Global Outcomes (KDIGO) Glomerulonephritis work group (2012) KDIGO clinical practice guideline for glomerulonephritis. Kidney Inter Suppl 2:139-274

24. Szczepiorkowski ZM, Winters JL, Bandarenko N, Kim HC, Linenberger ML, Marques MB, Sarode R, Schwartz J, Weinstein R, Shaz BH, Apheresis Applications Committee of the American Society for Apheresis (2010) Guidelines on the use of therapeutic apheresis in clinical practice-evidence-based approach from the Apheresis Applications Committee of the American Society for Apheresis. J Clin Apher 25:83-177. https://doi.org/10.1002/jca. 20240

25. Hunt EA, Jain NG, Somers MJ (2013) Apheresis therapy in children: an overview of key technical aspects and a review of experience in pediatric renal disease. J Clin Apher 28:36-47. https://doi. org/10.1002/jca.21260

26. Helander L, Hanna M, Annen K (2021) Pediatric double positive anti-glomerular basement membrane antibody and anti-neutrophil cytoplasmic antibody glomerulonephritis-a case report with review of literature. J Clin Apher 36:505-510. https://doi.org/10. 1002/jca. 21886

27. Weiss PF, Klink AJ, Friedman DF, Feudtner C (2012) Pediatric therapeutic plasma exchange indications and patterns of use in US children's hospitals. J Clin Apher 27:287-294. https://doi.org/10. 1002/jca.21242

28. O'Hagan E, Mallett T, Convery M, McKeever K (2015) AntiGBM disease after nephrectomy for xanthogranulomatous pyelonephritis in a patient expressing HLA DR15 major histocompatibility antigens: a case report. Clin Nephrol Case Stud 3:25-30. https://doi.org/10.5414/CNCS108594

29. Jiao LP, Fan JF, Sun Q, Shen Y (2012) Plasma exchange in Goodpasture syndrome associated with Turner's syndrome: a case report. Afr Health Sci 12:572-575. https://doi.org/10.4314/ahs. v12i4.29

30. Agarwal I, Al-Ghitany A (2017) Anti-glomerular basement membrane: a rare cause of renal failure in children. Saudi J Kidney Dis Transpl 28:379-383. https://doi.org/10.4103/1319-2442.202780

31. Mannemuddhu SS, Clapp W, Modica R, Elder ME, Upadhyay $\mathrm{K}$ (2019) End-stage renal disease secondary to anti-glomerular basement membrane disease in a child with common variable immunodeficiency. Clin Nephrol Case Stud 7:1-6. https://doi. org/10.5414/CNCS109510

32. Mayer U, Schmitz J, Brasen JH, Pape L (2020) Crescentic glomerulonephritis in children. Pediatr Nephrol 35:829-842. https:// doi.org/10.1007/s00467-019-04436-y

33. Dorval G, Lion M, Guerin S, Krid S, Galmiche-Rolland L, Salomon R, Boyer O (2017) Immunoadsorption in Anti-GBM glomerulonephritis: case report in a child and literature review. Pediatrics 140:e20161733. https://doi.org/10.1542/peds.2016-1733

34. Zhang YY, Tang Z, Chen DM, Gong DH, Ji DX, Liu ZH (2014) Comparison of double filtration plasmapheresis with immunoadsorption therapy in patients with anti-glomerular basement membrane nephritis. BMC Nephrol 15:128. https://doi.org/10.1186/ 1471-2369-15-128

35. Rivkees SA, Crawford JD (1988) The relationship of gonadal activity and chemotherapy-induced gonadal damage. JAMA 259:2123-2125

36. Heitz M, Carron PL, Clavarino G, Jouve T, Pinel N, GuebreEgziabher F, Rostaing L (2018) Use of rituximab as an induction therapy in anti-glomerular basement-membrane disease. BMC Nephrol 19:241. https://doi.org/10.1186/s12882-018-1038-7

37. Mori M, Nwaogwugwu U, Akers GR, McGill RL (2013) Antiglomerular basement membrane disease treated with mycophenolate mofetil, corticosteroids, and plasmapheresis. Clin Nephrol 80:67-71. https://doi.org/10.5414/cn107333

38. Marques C, Carvelli J, Biard L, Faguer S, Provot F, Matignon M, Boffa JJ, Plaisier E, Hertig A, Touzot M, Moranne O, Belenfant X, Annane D, Quemeneur T, Cadranel J, Izzedine H, Brechot N, Cacoub P, Piedrafita A, Jourde-Chiche N, Saadoun D (2019) Prognostic factors in anti-glomerular basement membrane disease: a multicenter study of 119 patients. Front Immunol 10:1665. https:// doi.org/10.3389/fimmu.2019.01665

39. Singh T, Kharadjian TB, Astor BC, Panzer SE (2021) Long-term outcomes in kidney transplant recipients with end-stage kidney disease due to anti-glomerular basement membrane disease. Clin Transplant 35:e14179. https://doi.org/10.1111/ctr.14179

40. Coche S, Sprangers B, Van Laecke S, Weekers L, De Meyer V, Hellemans R, Castanares D, Ameye H, Goffin E, Demoulin N, Gillion V, Mourad M, Darius T, Buemi A, Devresse A, Kanaan N (2021) Recurrence and outcome of anti-glomerular basement membrane glomerulonephritis after kidney transplantation. Kidney Int Rep 6:1888-1894. https://doi.org/10.1016/j.ekir.2021.04. 011

Publisher's note Springer Nature remains neutral with regard to jurisdictional claims in published maps and institutional affiliations. 